\title{
Reaction Monitoring by Means of Multivariate Data Analysis of Near-Infrared and Raman Spectra
}

\author{
Dardan Hetemi ${ }^{1,2^{*}}$ and Steve Janagap ${ }^{1,3}$ \\ ${ }^{1}$ Department of Chemistry, University of Bergen, Allégaten 41, N-5007 Bergen, Norway. \\ ${ }^{2}$ Pharmacy Department, Medical Faculty, University of Prishtina "Hasan Prishtina", Rr. "Dëshmorët e Kombit" p.n., \\ 10000 Prishtina, Kosovo. \\ ${ }^{3}$ Department of Chemistry, College of Arts and Sciences, University of the Philippines Visayas, \\ 5023 Miagao, Iloilo, Philippines. \\ *Corresponding author: E-mail: dardan.hetemi@uni-pr.edu
}

Received: 06-02-2017

\begin{abstract}
An efficient, versatile and non-destructive in situ method in reaction monitoring using vibrational spectroscopy is described. A Suzuki cross-coupling reaction was monitored in which the substrate 1-iodo-2-nitrobenzene reacted with the electrophile phenylboronic acid to form the product 2-nitrobiphenyl. To hasten the reaction, palladium(II) acetate and potassium carbonate were added to serve as catalyst and to promote transmetalation, respectively. This reaction was monitored using near-infrared and Raman spectroscopy. The recorded data was subjected to multivariate analysis such as principal component analysis in order to detect spectral changes due to the formation of the product. To confirm the presence of the desired product, offline analyses were performed using gas chromatography-mass spectrometry and nuclear magnetic resonance spectroscopy. The results demonstrate how Raman spectroscopy is able to detect the formation of the product in real time, whereas near-infrared spectroscopy fails to do so.
\end{abstract}

Keywords: Raman spectroscopy, near-infrared spectroscopy, reaction monitoring, Suzuki cross-coupling, multivariate data analysis

\section{Introduction}

Organic synthesis enables the creation of diverse chemical structures of complex architecture in the laboratory. New strategies to develop syntheses, optimize reaction outcomes, and investigate reaction mechanisms are important. One of the interesting reactions to synthesize substituted biphenyls ${ }^{1}$ involves the Suzuki cross-coupling reaction, a protocol of which has been disclosed elsewhere. ${ }^{2}$ The carbon-carbon bond construction method ${ }^{3,4,5,6}$ in organic synthesis has allowed chemists to assemble complex molecular frameworks to prepare numerous natural products, ${ }^{7}$ drug precursors, ${ }^{8}$ biological compounds, ${ }^{9}$ organic products ${ }^{10}$ and herbicides. ${ }^{11}$ Lately, the conditions developed for the cross-coupling reaction have many desirable features for large scale syntheses and are persuasively used in the industrial synthesis of pharmaceutical and chemical products. In daily laboratory work, time together with accuracy plays a crucial role in monitoring techniques particularly in in situ reactions.
Systems requiring long reaction times are frequently experienced in organic synthesis. For such reactions, in situ reaction monitoring techniques coupled with multivariate analysis serve as an excellent approach for determining reaction progress without interruption. Thus, online vibrational spectroscopy has become an increasingly useful tool for research and process development. ${ }^{12,13,14}$

Near-infrared (NIR) and Raman spectroscopy are suitable instrumental techniques in monitoring the formation of a desired product in real time. In comparison to gas chromatography-mass spectrometry (GC-MS) analysis which requires considerable time to provide a result, the NIR and Raman spectroscopic techniques provide an immediate response that considerably shortens analysis time. By these techniques, it is possible to obtain a huge amount of information about the reaction with minimum effort and time. ${ }^{15}$ Another advantage of NIR and Raman spectroscopy in reaction monitoring is that they can provide information on the appearance of reaction intermediates. 
They also give information about whether the reaction proceeds in the right direction. These advantages make NIR and Raman attractive techniques in pharmaceutical and industrial production.

The usefulness of the above-mentioned vibrational spectroscopic techniques in monitoring in situ reactions is much improved if they are coupled with proper data analysis. Chemometrics involves processing chemical data using mathematical and statistical methods in order to extract useful information. Principal components analysis (PCA $)^{16}$ is applied in order to extract chemical information from the spectra. Spectral data collected by NIR and Raman spectroscopy are complex and normally possesses broad overlapping absorption bands. A single NIR spectrum contains absorptions at many wavelengths that are measured at different times and the vast amount of spectrum generated by the instrument requires chemometric tools for analysis. Often, the measured absorbances at various wavelengths are highly correlated (they are not independent of each other) and this multicollinearity results to poor prediction. PCA is applied to significantly reduce the multidimensionality of the data while retaining most of the information where it decomposes the originally correlated variables to a new limited set of latent variables called principal components. These principal components represent the common variations in the data set where the first principal component accounts for most variations in the data; the second principal component explains the second greatest variations and so on. With PCA, data size is reduced and data overfitting is avoided.

In this study, a Suzuki cross-coupling reaction was investigated ${ }^{1}$ and monitored using NIR and Raman spectroscopy. The model reaction involved the palladium-catalyzed Suzuki cross-coupling of 1-iodo-2-nitrobenzene and phenylboronic acid to produce 2-nitrobiphenyl. The reaction protocol involves addition of a catalyst (palladium(II)

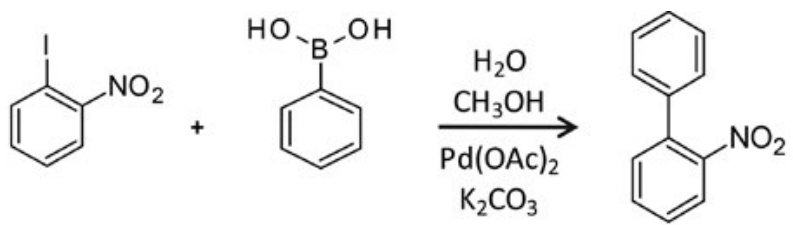

Scheme 1. Synthesis of 2-nitrobiphenyl. acetate) and a base (potassium carbonate) to promote transmetalation. Scheme 1 shows the synthesis of 2-nitrobiphenyl.

A review of literature revealed vast amount of materials concerning the Suzuki cross-coupling reaction ${ }^{4,5,17,18}$ but only few reports ${ }^{19,20}$ describe the use of NIR and Raman with the reaction. To the best of our knowledge, no report on combining NIR or Raman spectroscopy and multivariate analysis in monitoring Suzuki cross-coupling reactions have been published before. Thus, this study presents a novel monitoring of a Suzuki cross-coupling reaction through vibrational spectroscopic methods and multivariate data analysis.

As the Suzuki cross-coupling reactions lead to the formation of by-products as the reaction proceeds, the reaction time and other experimental conditions need to be monitored and controlled. Additionally, the monitoring should provide an immediate estimate of the progress of the ongoing reactions. This is important because Suzuki cross-coupling reactions give very low yield. The reaction of 2-chlorophenylboronic acid with 1-iodo-2-nitrobenzene has been reported as giving as little as $2 \%$ product yield ${ }^{1}$ under some conditions.

\section{Experimental Section}

\section{1. Chemicals}

1-Iodo-2-nitrobenzene ( $\geq 97 \%$ ), phenylboronic acid ( $\geq 99 \%)$, methanol ( $\geq 99.9 \%)$, dichloromethane ( $\geq 99.9 \%)$ and potassium carbonate $(\geq 99 \%)$ were purchased from Sigma-Aldrich (Missouri, USA). Palladium(II) acetate ( $\geq 98 \%$ ) was purchased from Fluka (Buchs, Switzerland). All products were used as received without further purification.

\section{2. Reaction Procedure}

The first step of the boscalid synthesis was chosen as a model for the Suzuki cross-coupling reaction. Instead of using 1-chloro-2-nitrobenzene as substrate for the synthesis of boscalid, an organohalide compound 1-iodo-2-nitrobenzene was used. This is due to the higher activity of ArI compared with $\mathrm{ArCl}$ in oxidative addition (ArI $>>\mathrm{Ar}-$

Table 1. Temperature, concentration and sampling times at each experiment run.

\begin{tabular}{ccccccccr}
\hline No. & T & C & \multicolumn{5}{c}{ Samples were withdrawn in specific time [min] } \\
exp. & {$\left[{ }^{\circ} \mathbf{C}\right]$} & {$[\mathbf{m m o l} / \mathbf{m L}]$} & Sample 1 & Sample 2 & Sample 3 & Sample 4 & Sample 5 & Sample 6 \\
\hline 1 & 23 & 0.167 & 60 & & & & & \\
2 & 50 & 0.167 & 60 & & & & & \\
3 & 60 & 0.167 & 5 & 10 & 15 & 30 & 45 & 60 \\
4 & 50 & 0.250 & 30 & 60 & & & & \\
1 & 60 & 0.250 & 5 & 10 & 15 & 30 & 45 & 60 \\
2 & 65 & 0.250 & 5 & 10 & 15 & 30 & 45 & 60 \\
\hline
\end{tabular}


$\mathrm{Br}>>\mathrm{ArCl}){ }^{21,22}$ The procedure for the synthesis of 2-nitrobiphenyl has been published elsewhere. ${ }^{1}$ Briefly, methanol $(5 \mathrm{~mL})$ and water $(1 \mathrm{~mL})$ were mixed in a round-bottom flask. Potassium carbonate $(0.414 \mathrm{~g}, 3 \mathrm{mmol})$, palladium(II) acetate $(0.006 \mathrm{~g}, 0.03 \mathrm{mmol}), 1$-iodo-2-nitrobenzene $(0.362 \mathrm{~g}, 1.5 \mathrm{mmol})$ and phenylboronic acid $(0.177 \mathrm{~g}$, $1.5 \mathrm{mmol}$ ) were then added to make the concentration $0.250 \mathrm{mmol} / \mathrm{mL}$ with respect to substrate (1-iodo-2-nitrobenzene). The solution was flashed with $\mathrm{N}_{2}$ gas and covered with aluminum foil. The reaction mixture was heated at 50 or $60^{\circ} \mathrm{C}$ under stirring. The reaction was monitored online with NIR and Raman methods. Samples were withdrawn at specific times without interrupting the reaction (as shown in Table 1), filtered through cotton and silica gel with dichloromethane and analyzed by GC-MS.

\section{3. Workup Procedure of Product}

Water $(30 \mathrm{~mL})$ was added to a crude product obtained after evaporation of methanol under reduced pressure. The solution was extracted three times with dichloromethane using $30 \mathrm{~mL}$ every extraction. The resulting organic solution was washed with saturated aqueous solution of sodium chloride $(30 \mathrm{~mL})$. The organic solution was evaporated under reduced pressure and the target product 2-nitrobiphenyl was obtained as dark yellowish oil and analyzed by NMR.

\section{4. Instrumentation}

A Perstorp NIR Systems 6500 (Maryland, USA) was used for recording the NIR spectra. The NIR spectra of the reaction mixture were obtained at specific time intervals using the fiber optic probe and were recorded from $1100-2500 \mathrm{~nm}$ range at $2 \mathrm{~nm}$ data interval and using 32 scans per spectrum. The path length was set to $0.5 \mathrm{~mm}$ using a $0.25 \mathrm{~mm}$ feeler gauge. An average of about $20 \mathrm{~s}$ was required to obtain one spectrum. Background and sample spectra were collected using the same parameter settings. The instrument control software used was Vision (FOSS NIRSystems, Inc., MD). The spectrum data was exported as an ASCII file. MATLAB 7.4 (The MathWorks Inc., Natick, MA) was used for multivariate analysis. The software was run on a Microsoft Windows 7 Professional 2009 operating system (Microsoft Corporation, WA, USA).

Raman scattering spectra were recorded on a RamanRxn1 analyzer (Kaiser Optical Systems, Inc., USA). Measurements were made with an immersion BallProbe ${ }^{\mathbb{B} 23}$ connected to the instrument via a fiber optic bundle. The laser wavelength and power were set to $785 \mathrm{~nm}$ and 100 $\mathrm{mW}$, respectively. The spectral range was from $0-3800$ $\mathrm{cm}^{-1}$ and spectral acquisition setting parameters were set (time of exposure was fixed to $2 \mathrm{~s}$; number of accumulations was set to two).
HoloGram 4.1 (Kaiser Optical Systems Inc., Michigan, USA) was used as the instrument control software. The recorded spectra were exported using HoloReact 2.0 (Kaiser Optical Systems Inc., Michigan, USA) to MATLAB. The Raman spectra were combined into one data matrix $\left(\mathrm{D}_{i \times j}\right)$ with dimensions $i \times j$, where $(i)$ represents spectra and $(j)$ represents frequencies.

The GC-MS used was HP 5890 II gas chromatograph coupled with HP 5971 mass spectrometer. The capillary column used was fused silica $(30 \mathrm{~m} \times 0.2 \mathrm{~mm}$ I.D. $)$ coated with Chrompack, CP-Sil 8 CB low bleed/ MS ( $0.25 \mu \mathrm{m}$ film thickness). The GC oven temperature was programed as follows: start temperature was $50^{\circ} \mathrm{C}$ ramped to $70{ }^{\circ} \mathrm{C}$ at 5 ${ }^{\circ} \mathrm{C} / \mathrm{min}$ then increased up to $300{ }^{\circ} \mathrm{C}$ at $25^{\circ} \mathrm{C} / \mathrm{min}$. Direct on-column injection was used, and the injector port temperature was $250^{\circ} \mathrm{C}$. Helium was used as carrier gas. Xcalibur 1.2 (Thermo Fisher Scientific Inc.) was used for instrument control and data analysis.

NMR spectra were recorded on a Bruker BioSpin DPX400 ( ${ }^{1} \mathrm{H}$ NMR: $400.13 \mathrm{MHz},{ }^{13} \mathrm{C}$ NMR: $\left.100.61 \mathrm{MHz}\right)$ spectrometer. Deuterated chloroform $\left(\mathrm{CDCl}_{3}\right)$ was used as solvent for the preparation of the samples and the internal standard. The chemical shifts were expressed in ppm values relative to tetramethylsilane (TMS). Multiplicities were reported using the following abbreviations: $\mathrm{s}$ (singlet), $\mathrm{d}$ (doublet), $\mathrm{t}$ (triplet), $\mathrm{q}$ (quartet), dd (double doublet) and $\mathrm{m}$ (multiplet). The spectra were recorded at room temperature and the data were processed with MestReNova 5.2 (Santiago de Compostela, Spain).

\section{Results and Discussion}

The reaction being monitored in this study is the synthesis of 2-nitrobiphenyl from 1-iodo-2-nitrobenzene and phenylboronic acid in the presence of palladium(II) acetate and potassium carbonate (see Scheme 1) via the Suzuki cross-coupling mechanism. To determine the best conditions that would give a high product yield, several factors were tested: amount of substrate (1-iodo-2-nitrobenzene), reaction temperature and time. It is therefore important to perform an optimization experiment by varying the levels of the variables and checking the yield at different time intervals as the reaction proceeds. In situ monitoring of the reaction was carried out by using NIR and Raman spectroscopy.

\section{1. Reaction Optimization}

Similar results were obtained in the synthesis of 2-nitrobiphenyl following the protocol described in a previous study, ${ }^{1}$ where $99 \%$ yield was achieved after 90 min reaction time at $20^{\circ} \mathrm{C}$. With the aim to shorten the reaction time (to $60 \mathrm{~min}$ ) but still obtaining a high yield, temperatures higher than $20^{\circ} \mathrm{C}$ were tested. Since reaction temperature and substrate concentration (1-iodo-2-nitrobenzene) are 
Table 2. Experimental set-up employed in the optimization procedure.

\begin{tabular}{ccccc}
\hline $\begin{array}{l}\text { Exp. } \\
\text { no. }\end{array}$ & $\begin{array}{c}\boldsymbol{T} \\
{\left[{ }^{\circ} \mathbf{C}\right]}\end{array}$ & $\begin{array}{c}\boldsymbol{C} \\
{[\mathbf{m m o l} / \mathbf{m L}]}\end{array}$ & $\begin{array}{c}\text { Time } \\
{[\mathbf{m i n}]}\end{array}$ & $\begin{array}{c}\text { Yield by } \\
\text { GC-MS [\%] }\end{array}$ \\
\hline 1 & 23 & 0.167 & 60 & 4.0 \\
2 & 50 & 0.167 & 60 & 35.3 \\
3 & 60 & 0.167 & 60 & 71.1 \\
4 & 50 & 0.250 & 60 & 49.2 \\
5 & 60 & 0.250 & 60 & 90.0 \\
6 & 65 & 0.250 & 60 & 99.7 \\
\hline
\end{tabular}

critical factors affecting the yield, several experiments were conducted by varying these factors, assigning low and high values. A summary of the optimization experiments is presented in Table 2. Results show consistently that the yield of the reaction increases as temperature is increased. The higher the temperature, the higher is the yield. When the concentration of the substrate is increased from 0.167 to $0.250 \mathrm{mmol} / \mathrm{mL}$, the same trend is observed: the greater the concentration of the substrate, the higher is the yield. This suggests that the substrate is stoichiometrically converted to the product, 2-nitrobiphenyl. The reaction carried out at $65{ }^{\circ} \mathrm{C}$ and $0.250 \mathrm{mmol} / \mathrm{mL}$ substrate concentration, afforded the highest reaction yield (99.7\%). This optimized reaction was monitored by means of fiber optical NIR and Raman spectroscopy (Figures 1 and 2).

\section{2. In Situ Vibrational Spectroscopy Monitoring}

Visual inspection of the NIR spectra (Figure 1) of the samples monitored from the start of the reaction until the end shows no noticeable spectrum profile changes to distinguish the appearance of the product 2-nitrobiphenyl.

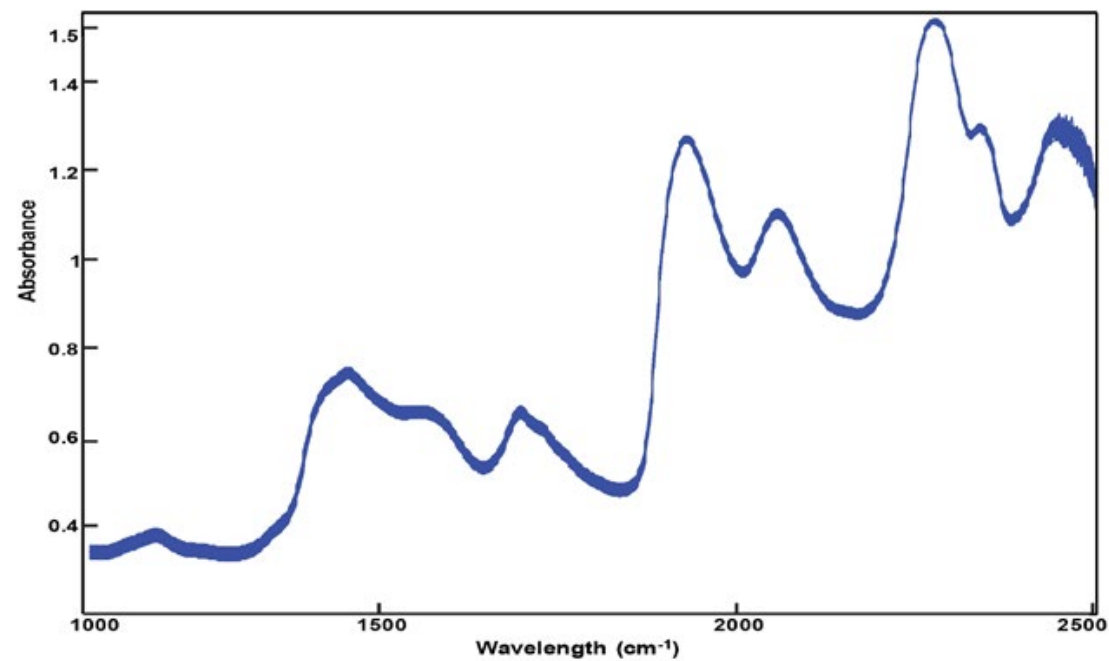

Figure 1. A series of NIR spectra recorded of a Suzuki cross-coupling reaction that was conducted at reaction temperature of $65^{\circ} \mathrm{C}$.

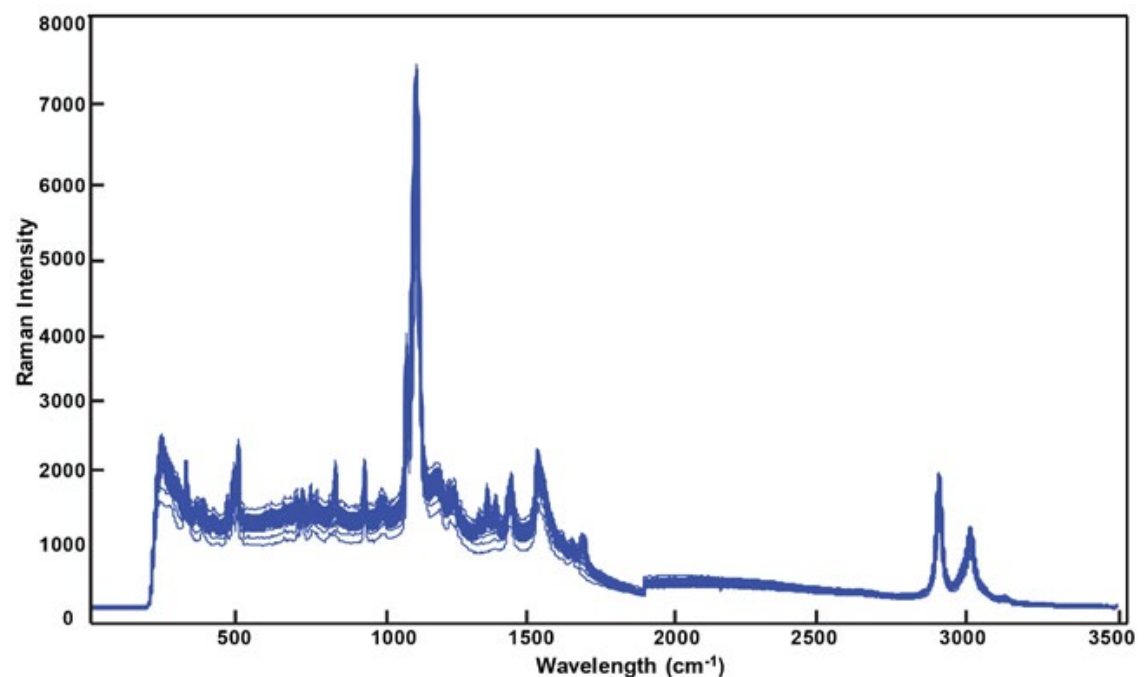

Figure 2. A series of Raman spectra recorded of a Suzuki cross-coupling reaction that was conducted at reaction temperature of $65^{\circ} \mathrm{C}$. 

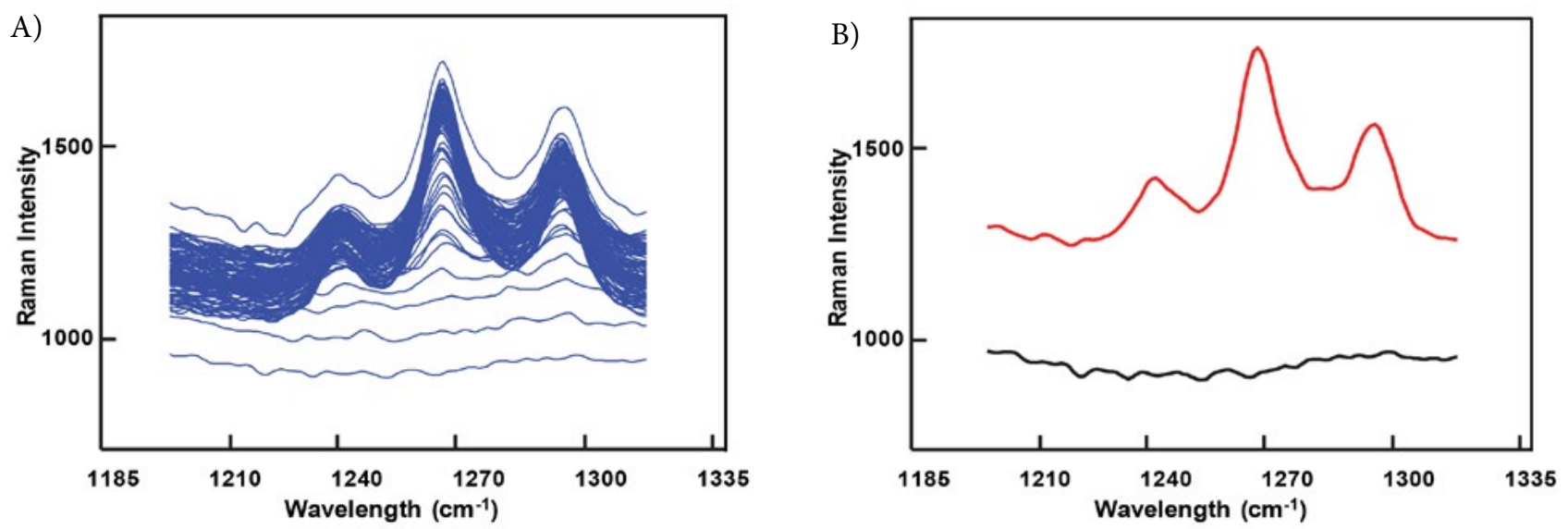

Figure 3. A) Magnified view of a specific region in the Raman spectra; B) The black and red spectra correspond to the first and last recorded spectra, respectively, as reaction proceeds.

By using principal component analysis (PCA), the data were pre-processed by mean-centering and first derivative method using $4^{\text {th }}$ order polynomial fit. ${ }^{24}$ Mean-centering and use of derivatives are pretreatment techniques to correct systematic variations in the NIR raw data between samples. The variations may be due to nonhomogeneous reaction mixing, sample density gradient, sample viscosity, and other factors that could affect the integrity of the samples during in situ sampling. These lead to light scattering effects and result in baseline shifts and scaling variations. Mean-centering and first derivative methods were selected as optimal pretreatments as they give the lowest statistical errors in preliminary data analysis. PCA was performed in the pretreated spectra to reduce the dimension of NIR spectra matrix for processing and handling multicollinearity. Emerged peak were analysed for the substrates and product (data not shown) and there were no significant profile changes in the spectra as reaction proceeds. This shows that NIR method is not sensitive in detecting formation of the product. On the other hand, the Raman spectra (Figure 2) show characteristic stretching vibrations of the biphenyl C-C bridge in the region 1200-1320 $\mathrm{cm}^{-1} \cdot{ }^{25,26,27}$ Spectral changes in this region signal conversion of the reactants (1-iodo-2-nitrobenzene and phenylboronic acid) into the desired product (2-nitrobiphenyl). To see more clearly, the region is magnified and presented in Figure 3A.

In Figure 3B, the black spectrum corresponds to the initial condition when the substrate was present in the reaction, while the red spectrum represents the final recorded spectrum, which shows the presence of the target molecule in the reaction mixture. The emergence of the peaks at the specific region $\left(1200-1320 \mathrm{~cm}^{-1}\right)$ in the last spectrum shows the emergence of the desired product (C-C bridge stretch of biphenyl). Further offline analysis by GCMS and NMR confirmed that the spectral changes could be attributed to the formation of the product 2-nitrobiphenyl via the Suzuki cross-coupling reaction. The GC-MS chromatogram and NMR spectrum are presented in Supporting Information.

\section{3. Multivariate Data Analysis}

Principal component analysis (PCA) is an exploratory technique that highlights the differences in the spectra collected and gives a simple visual idea as to the relationship between the spectra. By using PCA, we have analysed the emerged peak for the substrates and product (data not shown). No significant change that could be attributed to the formation of the product was observed. In the contrary, good results were obtained for the specific region $\left(1200-1320 \mathrm{~cm}^{-1}\right)$ in the Raman spectra treated with PCA where the data matrix $(120 \times 120)$ was pre-processed using the same techniques as for NIR data. The first principal component (PC1) explains $87.91 \%$ of the total variance and from the sample and score plot (Figure 4), it is possible to establish a time-concentration profile.

Figure 4 shows that the concentration of the product increases proportionally with time. This increase continues until the reaction is complete. During the course of the reaction, a series of spectra were recorded every $30 \mathrm{~s}$ so the sample 120 corresponds to the time of $60 \mathrm{~min}$, the end of reaction monitoring $(99.7 \%$ yield by GC-MS). The curve shows that the reaction has almost finished after $30 \mathrm{~min}$ (corresponding to sample 60). This is in full agreement with the offline measurements of GCMS that shows the yield of $98.3 \%$ for 30 min (Table 3). Also, in the beginning of the reaction (blue circle in Figure 4) we do not have the product yet so the black curve is not increasing. All offline measurements for GC-MS can be seen in the Table 3.

As mentioned earlier, PCA was also performed in the NIR data and results show that no significant findings can be established from the collected data. NIR instrumentation is inadequate for monitoring the reaction due to low sensitivity of detection. This study shows that Ra- 


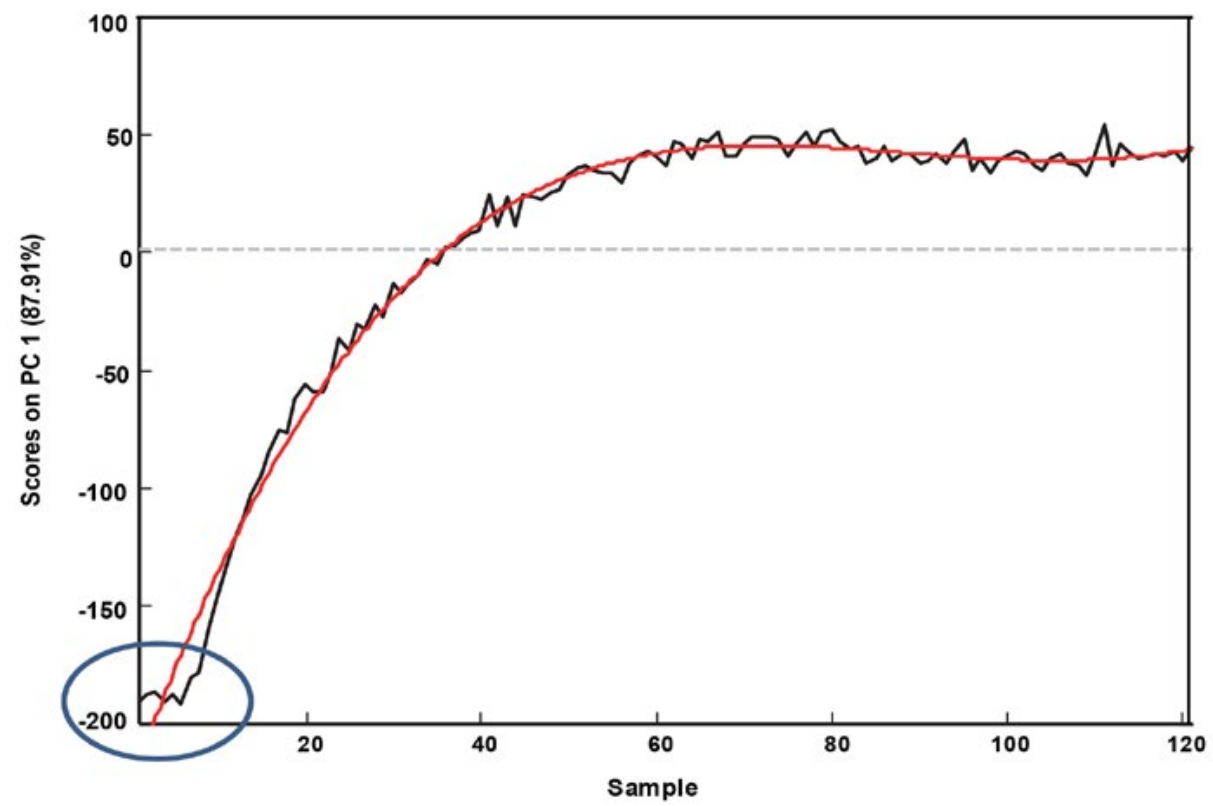

Figure 4. Samples and scores plot of the data in $1200-1320 \mathrm{~cm}^{-1}$ region. The red line shows the $4^{\text {th }}$ degree polynomial fit.

Table 3. The time of sample withdrawn and the yield measured by GC-MS.

\begin{tabular}{cc}
$\begin{array}{c}\text { Time } \\
{[\text { min] }}\end{array}$ & $\begin{array}{c}\text { Yield by } \\
\text { GC-MS [\%] }\end{array}$ \\
\hline 0 & 0 \\
5 & 59.5 \\
10 & 79.8 \\
15 & 87.9 \\
30 & 98.3 \\
45 & 99.6 \\
60 & 99.7 \\
\hline
\end{tabular}

man spectroscopy is more sensitive and is the appropriate technique over NIR in reaction monitoring.

\section{Conclusions}

Monitoring of reactions using vibrational spectroscopy coupled with multivariate data analysis finds very important applications nowadays in pharmaceutical and chemical industries. The possibility of online detection of a desired product in an ongoing chemical reaction without system interruption is the main advantage why these techniques in combination with PCA have wide use in the industry. Monitoring of reactions in industry commonly uses the NIR method but this present paper demonstrated that the Raman method is more sensitive and effective and thus, suitable for reaction monitoring.

The power of multivariate technique such as PCA in combination with the Raman instrumentation has been shown. The Raman results have been validated by offline techniques such as GC-MS and NMR. Results of online and offline techniques confirm the detection of the desired product making feasible the monitoring of a Suzuki cross-coupling reaction by real time Raman spectroscopy.

\section{Acknowledgments}

European Commission (Erasmus Mundus Scholarships) and University of Bergen are acknowledged for funding the project. The former is acknowledged for financial support.

\section{Supporting Information} nyl.

GC-MS of 2-nitrobiphenyl; H NMR of 2-nitrobiphe-

\section{References}

1. R. R. Gonzale, L. Liguori, A. M. Carrillo, H.-R. Bjørsvik, J. Org Chem. 2005, 70, 9591-9594. DOI:10.1021/jo051589t

2. N. Miyura, K. Yamada, A. Suzuki, Tetrahedron Lett. 1979, 20 , 3437-3440. DOI:10.1016/S0040-4039(01)95429-2

3. E. Negishi, Acc. Chem. Res. 1982, 15, 340-348. DOI:10.1021/ar00083a001

4. A. Suzuki, J. Organomet. Chem, 1999, 576, 147-168. DOI:10.1016/S0022-328X(98)01055-9

5. N. Miyaura, Chem. Rev. 1995, 95, 2457-2483.

DOI:10.1021/cr00039a007 
6. L. Zhao, F. Derridj, S. Djebbar, Ch. Bruneau, H. Doucet, Tetrahedron Lett. 2015, 56, 4354-4358.

DOI:10.1016/j.tetlet.2015.05.082

7. S. J. Danishefsky, J. J. Masters, W. B. Yound, J. T. Link, L. B. Snyder, Th. V. Magee, D. K. Jung, R. C. A. Isaacs, W. G. Bornmann, Ch. A. Alaimo, C. A. Coburn, M. J. Di Grandi, J. Am. Chem. Soc. 1996, 118, 2843-2859.

DOI:10.1021/ja952692a

8. H. A. Saader, I. M. Mosleh, M. M. El-Abadelah, Molecules, 2009, 14, 2758-1767. DOI:10.3390/molecules 14082758

9. X. Zheng, W. Meng, F. Qing, Tetrahedron Lett. 2004, 45, 80838085. DOI:10.1016/j.tetlet.2004.08.180

10. A. Ganesan, Drug Discovery Today, 2002, 7, 47-55. DOI:10.1016/S1359-6446(01)02087-6

11. H. H. Szmant, Organic building blocks of the chemical industry. Wiley: New York,1989, Chapter 4.

12. I. Marziano, D. C. A. Sharp, P. J. Dunn, P. A. Hailey, Org. Process Res. Dev. 2000, 4, 357-361.

DOI:10.1021/op000030m

13. K. Hossain, H. Y. Cho, K. J. Kim, J. W. Choi, Biosens. Bioelectron. 2015, 71, 300-305. DOI:10.1016/j.bios.2015.04.053

14 . Y. Wu, Y. Jin, Y. Li, D. Sun, X. Liu, Y. Chen, Vib. Spectrosc. 2012, 58, 109-118.

DOI:10.1016/j.vibspec.2011.10.006

15. W. L. Guo, Y. P. Du, Y. C. Zhou, S. Yang, J. H. Lu, H. Y. Zhao, Y. Wang, L. R. Teng, World J. Microbiol. Biotechnol. 2012, 28, 993-1002. DOI:10.1007/s11274-011-0897-x
16. I. T. Jollife, Principal Component Analysis; Springer: New York, 2002.

17. S. D. Dreher, S.-E. Lim, D. L. Sandrock, G. A. Molander, J. Org. Chem., 2009, 74, 3626-3631. DOI:10.1021/jo900152n

18. M. P. Lorenzo, J. Phys. Chem. Lett. 2012, 3, 167-174. DOI:10.1021/jz2013984

19. G.; Rothenberg, S. C. Cruz, G. P. F. van Strijdonck, H. C. J. H. Hoefsloot, Adv. Synth. Catal. 2004, 346, 347- 473.

20. N. E. Leadbeater, R. J. Smith, Org. Lett. 2006, 8 , 4589-4591. DOI:10.1021/ol061803f

21. A. F. Littke, Ch. Dai, G. C. Fu, J. Am. Chem. Soc. 2000, 122, 4020-4028. DOI:10.1021/ja0002058

22. H. Kurosawa, A. Yamamoto, (Ed.): Fundamentals of Molecular Catalysis, Current Method in Inorganic Chemistry; Vol.3; Elsevier Science, Tokyo, Japan 2003, pp.115-123.

23.http://ballprobe.com/index.html (accessed: March 14, 2016).

24. A. Savitzky, M. J. E. Golay, Anal. Chem., 1964, 38, 1627-1639. DOI:10.1021/ac60214a047

25. J. S. Gromiuk, H. Gluchowska, B. Tarsiuk, L. Mazur, Z. Rzaczynska, J. Mol. Struct. 2014, 1070, 110-116. DOI:10.1016/j.molstruc.2014.04.030

25. K. C. Bantz, Ch. L. Haynes, Vib. Spectrosc. 2009, 50, $29-35$. DOI:10.1016/j.vibspec.2008.07.006

27. G. Socrates, Infrared and Raman Characteristic Group Frequencies: Tables and Charts, 3rd ed., Wiley: New York, 2001.

\section{Povzetek}

Opisujemo učinkovito, vsestransko in neporušno »in situ« metodo za spremljanje reakcij z uporabo vibracijske spektroskopije. Spremljali smo Suzukijevo reakcijo, pri kateri je substrat 1-jodo-2-nitrobenzen reagiral z elektrofilom fenilborovo kislino in tvoril produkt 2-nitrobifenil. Da bi pospešili reakcijo, smo dodali paladijev(II) acetat kot katalizator in kalijev karbonat, ki promovira reakcijo transmetalacije. To reakcijo smo spremljali z bližnjo infrardečo in $\mathrm{z}$ Ramansko spektroskopijo. Podatke smo obdelali z multivariantno analizo, kot je metoda glavnih osi (PCA), da bi ugotovili, do katerih sprememb v spektrih pride zaradi nastanka produkta. Za potrditev prisotnosti želenega produkta smo izvajali tudi "off-line« analizo s plinsko kromatografijo-masno spektrometrijo in z jedrsko magnetno resonančno spektroskopijo. Rezultati pokažejo, da z Ramansko spektroskopijo lahko zaznamo tvorbo produkta v realnem času, medtem ko z bližnjo infrardečo spektroskopijo to ni možno. 